Thorax (1976), 31, 55.

\title{
Elective operations for post-infarction left ventricular aneurysms
}

\author{
COSTAS G. SBOKOS, J. L. MONRO, \\ and J. KEITH ROS S \\ Wessex Cardiac and Thoracic Centre, Southampton
}

\begin{abstract}
Sbokos, C. G., Monro, J. L., and Ross, J. K. (1976). Thorax, 31, 55-62. Elective operations for post-infarction left ventricular aneurysms. During a two-year period (February 1973 to February 1975) 20 consecutive patients with post-infarction left ventricular aneurysm, seen at the Wessex Cardiac and Thoracic Centre, underwent aneurysmectomy with or without aorta-to-coronary artery saphenous vein bypass grafts, ventricular septal defect closure, or valve replacement.

The diagnoses were established by clinical means, plain chest radiographs, left ventriculography, and selective coronary arteriography. The indications for surgery were uncontrollable congestive heart failure and angina, ventricular arrhythmias, or a rapidly growing aneurysm. Low cardiac indices or high left ventricular end-diastolic pressure were not considered to be contraindications to operation. Resection of the left ventricular aneurysm was performed with the use of normothermic cardiopulmonary bypass with haemodilution. In addition to the aneurysmectomy, four of these patients had concomitant closure of post-infarction ventricular septal defects; four had valve replacements; two had grafts to coronary arteries; and one had both replacement of the mitral valve and a right coronary vein graft.

There were two hospital deaths $(10 \%)$ and two late deaths $(10 \%)$, making an overall mortality of $20 \%$. All but one of the deaths were related to coronary artery disease. The survivors are active, and their rehabilitation was satisfactory. The longest survivor is doing well two years after left ventricular aneurysmectomy, ventricular defect closure, and tricuspid valve replacement.

It is evident from our experience and from the reports of others that surgery has an established place in the management of post-infarction left ventricular aneurysm.
\end{abstract}

Left ventricular aneurysm is a complication of myocardial infarction and seriously reduces the chances of survival. In a collected series of 102 patients with left ventricular aneurysm, Schlichter, Hellerstein, and Katz (1954) found that $73 \%$ died within three years, and $88 \%$ within five years, due to intractable heart failure, repetitive arrhythmias, recurrent myocardial infarction, or systematic embolization. Left ventricular aneurysm has been reported to occur in 8 to $38 \%$ of patients following myocardial infarction (Schlichter et al., 1954; Abrams et al., 1963; Gorlin, Klein, and Sullivan, 1967; Tassel and Edwards, 1972), this wide variation in calculated incidence being caused mainly by difficulty in agreement on an accurate definition of a ventricular aneurysm.

Ventricular aneurysm was present in $3.5 \%$ in a series of 2293 myocardial infarctions in 10800 consecutive necropsies at the Mayo Clinic (Dubnow, Burchell, and Titus, 1965). Abrams et al. (1963) found at necropsy that ventricular aneurysms were present in $12.4 \%$ of patients with myocardial infarction.

The first successful aneurysmectomy without the use of cardiopulmonary bypass was reported in 1955 by Likoff and Bailey. Since Cooley et al. (1958) performed the first excision of a left ventricular aneurysm under cardiopulmonary bypass, resection of ventricular aneurysms has become a well-established surgical procedure (Lam et al., 1966; Cooley and Hallman, 1968; Favaloro et al., 1968; Ibarra-Pérez and Lillehei, 1969; Schattenberg et al., 1970; Kluge et al., 1971; Loop, 1971; Austen, 1973; Merin et al., 1973; Rao et al., 1974; Cooperman et al., 1975). The first British report of successful open excision was by Telling and Wooler (1961). 
The recognition of ventricular aneurysms is of practical importance as surgical repair is advocated. Intractable cardiac failure, uncontrolled arrhythmias, and systemic embolism are the main indications for aneurysmectomy. Occasionally other mechanical problems, such as an associated ventricular septal defect or mitral regurgitation, also need correction. Combined revascularization should probably be undertaken in vessels that have considerable narrowing and still supply functioning myocardium (Thind, Blakemore, and Zinsser, 1971; Austen, 1973; Davis et al., 1973; Gerbode et al., 1974; Cooperman et al., 1975).

This paper presents our clinical experience with the management of 20 consecutive patients by a reasonably aggressive surgical approach.

\section{PATIENTS AND METHODS}

During the two-year period from February 1973 to February 1975, 20 patients were referred to the Wessex Cardiac and Thoracic Centre, Southampton for evaluation and treatment of left ventricular aneurysm. Of the 20 patients, $14(70 \%)$ were men and $6(30 \%)$ women. Their ages ranged from 35 to 74 years, with an average age of 58 , and $60 \%$ were more than 60 years of age.

All the patients had had at least one myocardial infarction, $70 \%$ had persistent congestive heart failure, $10 \%$ cardiac failure and angina, and $20 \%$ had repetitive arrhythmias, varying from rapid atrial fibrillation to intractable ventricular tachycardia or fibrillation (Table I).

T A B L E I

PRESENTATION AND INDICATION FOR OPERATION 20 PATIENTS

\begin{tabular}{l|r|r}
\hline \multicolumn{1}{c|}{ Main Symptom } & \multicolumn{2}{|c}{ Patients } \\
\cline { 2 - 3 } & No. & $\%$ \\
\hline Congestive heart failure & 14 & 70 \\
Arrhythmia & 1 & 5 \\
Angina & 0 & - \\
Arterial emboli & 0 & - \\
Congestive heart failure and arrhythmia & 3 & 15 \\
Congestive heart failure and angina & 2 & 10 \\
\hline
\end{tabular}

There was no preoperative embolization.

An average of 8.5 months (range 19 days to 2 years) had elapsed between the initial infarction and the diagnosis of the aneurysm. The mean time interval between infarction and operation was 13.6 months (range 23 days to 5 years). Only five patients $(25 \%)$ had systemic hypertension.

There were no pathognomonic physical findings, although clinical examination disclosed a forceful and rather broad systolic expansion of the chest wall in eight patients. Chest radiographsc showed cardiac enlargement and a distinct circum- $\frac{\overline{0}}{\overline{5}}$ scribed bulging of the extreme left ventricular contour. In our series, the diagnosis could be $\varrho$ made on the plain chest radiograph alone in $12 \mathrm{cs}$ out of 20 patients (Figs 1-3). With one exception, $\overrightarrow{0}$ all patients had been studied by left ventriculography, to determine the size and site of thew aneurysm, the contractility of the unaffected pars of the ventricle, and the presence or absence of mitral incompetence.

Selective coronary arteriography was routinely performed, to identify the distribution of ther coronary artery disease and to allow planning ofo myocardial revascularization. The aneurysm was located in the anterolateral wall or involving the apex of the left ventricle in 17 out of 20 patients? $(85 \%)$. Two were posterior, and one (superior) was situated high at the topmost part of the lef $\bar{k}$ ventricle, lateral to the pulmonary artery ande just beneath the aortic valve (Fig. 3a).

Four patients were found to have, in addition to their aneurysm, a postinfarction ventricularo septal defect, and another four had severe mitrab regurgitation due to papillary muscle dysfunctiono (3 patients) or rheumatic valvular disease (1\% patient) (Tables II and III).

In all 17 patients with anterolateral or apica aneurysms, the left anterior descending coronary artery was occluded. In both patients with of posterior ventricular aneurysm, the right coronary artery and/or the circumflex were occluded $\overrightarrow{0}$ associated with mitral regurgitation in one patient, and ventricular septal defect in the other. In the patient with the superior aneurysm and mitral re-3.3. gurgitation, the left anterior descending coronaryo artery was normal, but there was significants stenosis of the circumflex and right coronaryo arteries.

In two of the three patients with associated mitral regurgitation due to papillary muscle dys function, the left anterior descending coronaryo artery was normal, but there was occlusion of either the circumflex or the right coronary artery or both (Table II).

In all patients with postinfarction ventricular septal defect, either one or both of the non occluded remaining major coronary arteries weres also seriously diseased.

The left ventricular end-diastolic pressure waso routinely measured and found to be elevated in over two-thirds of the patients.

The operative findings agreed with the pre $\frac{\mathbb{D}}{8}$ operative assessment in all patients. The size and site of the aneurysm, the presence of mitrab 

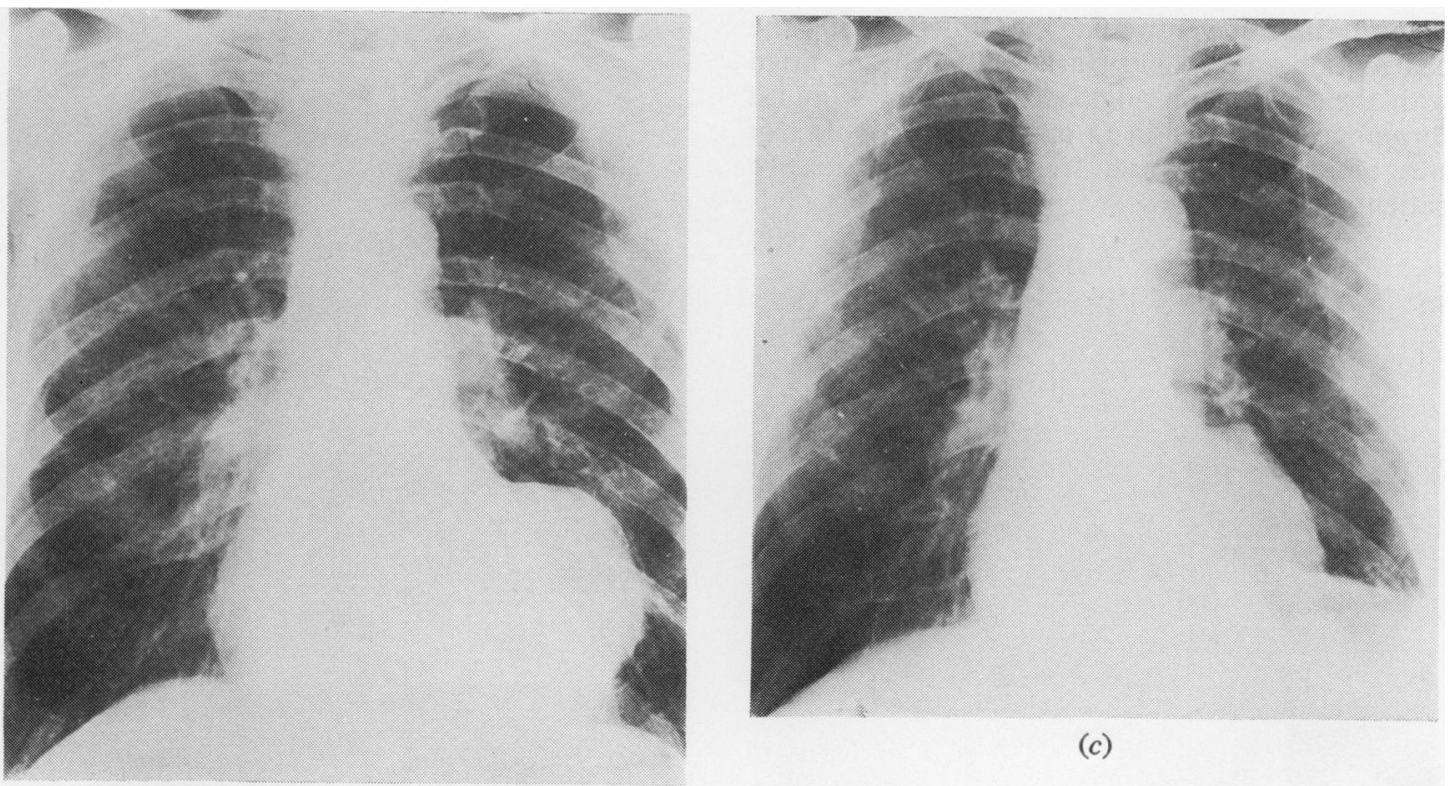

(c)

(a)


(b)

$(d)$

FIG. 1. Chest radiographs in a 69-year-old patient with a left ventricular aneurysm and severe mitral regurgitation, before and after aneurysmectomy and mitral valve replacement. (a) Large aneurysm at the left heart border. (b) Lateral view showing the posterior aneurysm extending up to the atrioventricular groove. $(c$ and d) Postero-anterior and lateral views five months after operation. 
regurgitation or ventricular septal defect, and the distribution of coronary artery disease all fitted with the findings on angiocardiography. A mural thrombus was found in 13 patients $(65 \%)$, old clot was present in 11, and fresh thrombus in two patients.

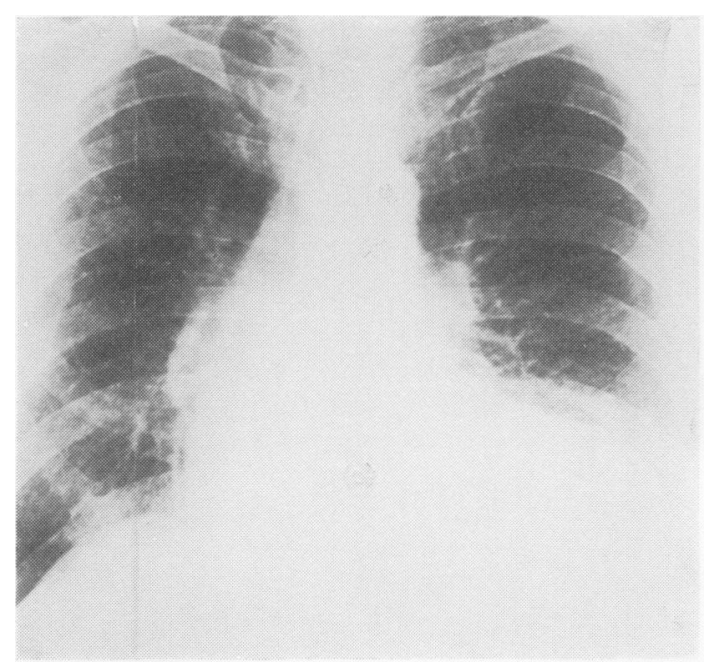

(a)

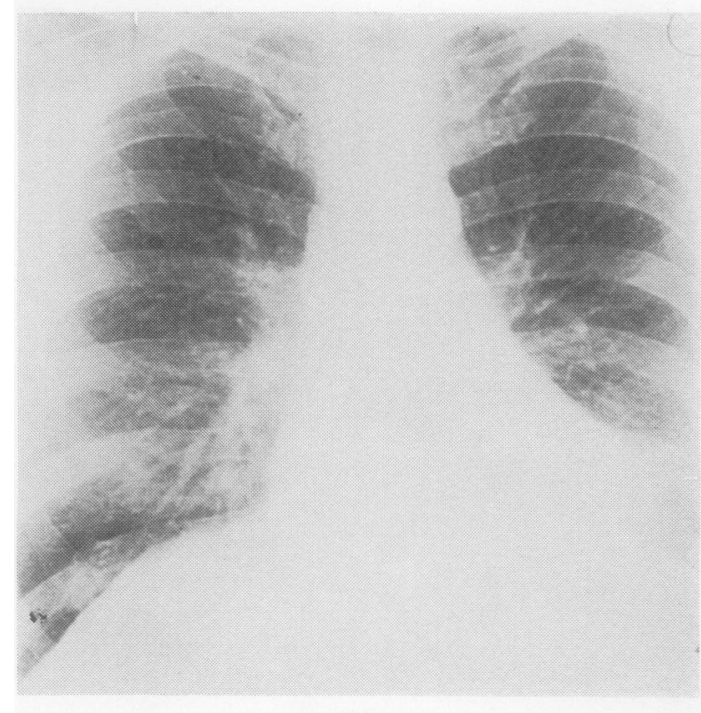

(b)

FIG. 2. (a) Chest radiograph showing a large left ventricular aneurysm in a 58-year-old man. (b) The postoperative film, two months after resection of the aneurysm, showing a considerable decrease in heart size.

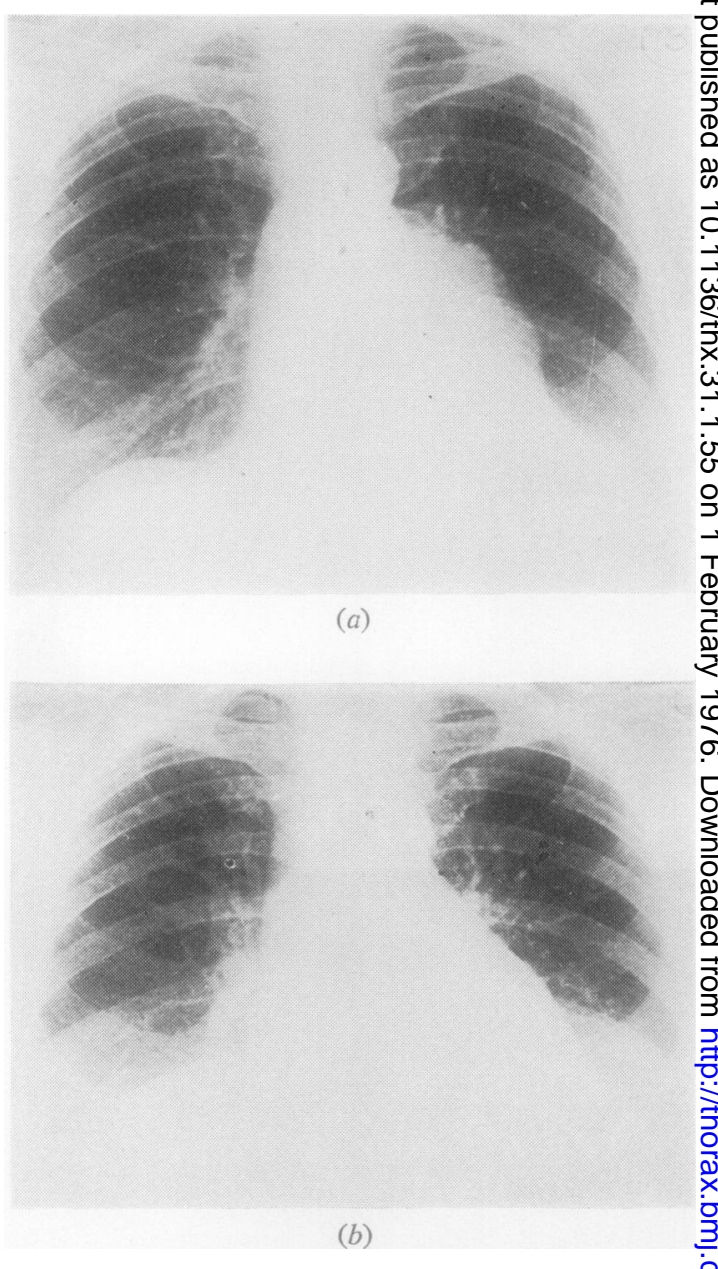

FIG. 3. Chest radiographs (a) before and (b) two months after resection of an aneurysm arising from the upper portion of the free wall of the left ventricle and mitral valve replacement.

OPERATIVE TECHNIQUE Excision of the left ventriN cular aneurysm was performed in 18 , and $\bar{\alpha}$ plication technique in two patients. All were operated upon using cardiopulmonary bypass with normothermia and aortic cross-clamping. The lef ventricle was never manipulated before clamping of the aorta, so avoiding embolization from dis lodged mural thrombus. This technical point is considered important. We encountered only one example of intraoperative embolism, when a piece्ष of thrombus was discovered in and was removed from the left coronary ostium. This illustrates the need for exploration of the coronary ostia if the ventricle fails acutely after bypass. 
T A B L E I I

CORRELATION OF CORONARY ANATOMY, LOCATION OF ANEURYSM AND ASSOCIATED LESION - 20 PATIENTS

\begin{tabular}{l|l|c|c}
\hline $\begin{array}{c}\text { Anatomical Distribution } \\
\text { of Coronary Diseases }\end{array}$ & $\begin{array}{c}\text { Location of } \\
\text { Aneurysm }\end{array}$ & $\begin{array}{c}\text { Associated } \\
\text { Lesion }\end{array}$ & $\begin{array}{c}\text { No. of } \\
\text { Cases }\end{array}$ \\
\cline { 1 - 2 } $\begin{array}{c}\text { Occluded LAD with good } \\
\text { RCA and CCA }\end{array}$ & Anterolateral & - & 10 \\
$\begin{array}{c}\text { Occluded LAD and CCA } \\
\text { with good RCA }\end{array}$ & Anterolateral & VSD & 1 \\
$\begin{array}{c}\text { Occluded LAD and RCA } \\
\text { with good CCA }\end{array}$ & Anterolateral & MR & 1 \\
$\begin{array}{c}\text { Multiple CAD } \\
\text { Occluded CCA with good }\end{array}$ & $\begin{array}{c}\text { Anterolateral } \\
\text { PAD and RCA }\end{array}$ & Vosterior & 2 \\
$\begin{array}{c}\text { Occluded CCA and RCA } \\
\text { with good LAD }\end{array}$ & Posterior & MR & 1 \\
\hline
\end{tabular}

Occluded $=$ more than $80 \%$ stenosis

LAD = left anterior descending coronary artery

RCA = right coronary artery

CCA = circumflex coronary artery

CAD = coronary artery disease

VSD = ventricular septal defect

MR = mitral regurgitation

T A B L E I I I

LEFT VENTRICULAR ANEURYSM: CLASSIFICATION IN 20 PATIENTS

\begin{tabular}{l|c|c|c}
\hline \multicolumn{1}{c|}{ Pathology } & $\begin{array}{c}\text { Number } \\
\text { of } \\
\text { Patients }\end{array}$ & $\begin{array}{c}\text { Hospital } \\
\text { Death }\end{array}$ & $\begin{array}{c}\text { Late } \\
\text { Death }\end{array}$ \\
\hline $\begin{array}{l}\text { Simple LAD aneurysm } \\
\text { good RCA and CCA }\end{array}$ & 10 & 1 & 2 \\
$\begin{array}{c}\text { Simple LAD aneurysm needing } \\
\text { circumflex vein graft }\end{array}$ & 1 & - & - \\
$\begin{array}{c}\text { Ventricular aneurysm + VSD } \\
\text { Aneurysm needing valve } \\
\text { replacement }\end{array}$ & 4 & 1 & - \\
$\begin{array}{c}\text { Aneurysm needing MVR + RCA } \\
\text { vein graft }\end{array}$ & 4 & - & - \\
\hline
\end{tabular}

${ }^{1}$ Left ventricular aneurysm in the region supplied by the left anterior descending coronary artery which is occluded

MVR = mitral valve replacement

Once the aneurysm had been opened and clot removed, the aortic clamp was released in some patients. In the remainder the whole procedure was carried out with the aorta cross clamped. The average ischaemic time was 22 minutes

Once the aneurysm had been incised over its summit and any thrombus removed, the left ventricular cavity was carefully inspected and the relationship of the infarct to the septum and papillary muscles was defined. Excision of the sac was carried out, leaving a narrow rim of fibrous tissue to provide support for sutures.

Often quite extensive areas of fibrous scar had to be left on the septal side, but this did not impair the mechanical results, possibly because (in patients who have not progressed to septal rupture) the full thickness of the septum was not involved in the infarct.

Ventricular septal defects were closed with interrupted mattress sutures tied over Dacron felt buttresses with a Dacron patch, and always from the left side. The ventriculotomy was closed using interrupted or continuous heavy silk or mersilene mattress sutures over a double strip of Teflon felt, followed by a second continuous over and over suture.

An additional surgical procedure was performed in combination with aneurysmectomy in half the patients (Table IV). Four patients underwent simultaneous closure of postinfarction ventricular septal defect. One of these had severe tricuspid regurgitation (not due to ruptured chordae or papillary muscle), and an attempt was made to control this by annuloplasty. This failed, and tricuspid valve replacement (with a Starr Edwards valve) the next day was followed by immediate improvement and an excellent late result. Three patients had concomitant mitral valve replacement; one an aortic valve replacement with an antibiotic sterilized aortic homograft; one had a saphenous vein bypass graft to the circumflex coronary artery; and another underwent mitral valve replacement and vein bypass graft to the right coronary artery in addition to aneurysmectomy.

T A B L E I V

ANEURYSMECTOMY, ASSOCIATED PROCEDURES, AND OPERATIVE RESULTS IN 20 PATIENTS

\begin{tabular}{l|c|c|c}
\hline \multicolumn{1}{c|}{ Procedure } & $\begin{array}{c}\text { Number } \\
\text { of } \\
\text { Patients }\end{array}$ & $\begin{array}{c}\text { Hospital } \\
\text { Death }\end{array}$ & $\begin{array}{c}\text { Late } \\
\text { Death }\end{array}$ \\
\hline $\begin{array}{c}\text { Ventricular aneurysmectomy } \\
\text { Ventricular septal defect closure } \\
\text { and aneurysmectomy }\end{array}$ & 10 & 1 & 2 \\
$\begin{array}{c}\text { Mitral valve replacement and } \\
\text { aneurysmectomy }\end{array}$ & 4 & 1 & - \\
$\begin{array}{c}\text { Circumflex coronary artery vein } \\
\text { graft and aneurysmectomy } \\
\text { Mitral valve replacement, right } \\
\text { coronary artery vein graft, and } \\
\text { aneurysmectomy }\end{array}$ & 1 & - & - \\
$\begin{array}{c}\text { Aortic valve replacement } \\
\text { (homograft) and aneurysmectomy }\end{array}$ & 1 & - & - \\
\hline
\end{tabular}

${ }^{1}$ In one patient plus tricuspid annuloplasty, but without satisfactory result: reoperation on first postoperative day and tricuspid valve replacement with Starr Edwards prosthesis. The final result was excellent.

${ }^{2}$ In one patient there was a history of mitral valve disease many years before myocardial infarction and ventricular aneurysm development.

Cardiac failure and arrhythmia were the most common postoperative complications and responded to medical treatment. There was one re-exploration of the wound for tamponade.

\section{RESULTS}

The hospital mortality was $10 \%$ (two hospital deaths) and there were two late deaths $(10 \%)$, giving an overall majority of $20 \%$ (Table V).

Of the two hospital deaths, one was a 57-yearold man who had a myocardial infarction 23 days before operation for ventricular septal defect 
T A B L E V

MORTALITY - 20 PATIENTS

\begin{tabular}{l|c|c}
\hline Death & No. & $\%$ \\
\hline Hospital & 2 & 10 \\
Late & 2 & 10 \\
Total & 4 & 20 \\
\hline
\end{tabular}

closure and plication of left ventricular aneurysm. $\mathrm{He}$ had had two episodes of cardiac arrest but was successfully resuscitated. He underwent another cardiac arrest on the day of operation, and an emergency procedure was carried out. He made reasonable progress and was extubated on the second postoperative day, but the day after he suffered another cardiac arrest, and attempts to resuscitate failed. Necropsy revealed long-standing multiple coronary vessel occlusion.

The second hospital death was in a 62-year-old man, who underwent aneurysmectomy for a large ventricular aneurysm five months after the causative myocardial infarction, and who died at operation from low cardiac output due to diffuse coronary artery disease. Necropsy showed a very small residual left ventricular cavity, with evidence of severe widespread coronary artery disease.

Of the late deaths, one was a man of 44 with preoperative arrhythmias, including on one occasion ventricular fibrillation and circulatory arrest. He initially did well postoperatively but died suddenly three months after operation. Necropsy disclosed a recent myocardial infarction.

The second late death was directly due to a recurrence of the aneurysm. Eleven months after aneurysmectomy, the patient, again symptomatic, required reoperation for a false aneurysm which had developed at the site of the original ventriculotomy. After resection of the false aneurysm and repair of the ventricle, the small and noncompliant residual ventricle caused the patient's death on the operating table.

The postoperative course of the survivors was smooth, with an average hospital stay of 18 days after operation. All but one are leading active lives; the latter still requires medical treatment for diffuse coronary artery disease.

\section{DISCUSSION}

The major mechanical complications of myocardial infarction are ventricular aneurysm, rupture or dysfunction of papillary muscles, ventricular septal defect, and acute cardiac rupture (Abrams et al., 1963; Dubnow et al., 1965; Gorlin et al., 1967; Tassel and Edwards, 1972).
The wide variation $(8 \%$ to $38 \%)$ in the incidence of aneurysm following myocardial infarction is probably explained by the different diag- $\frac{\overline{\bar{N}}}{\overline{\mathrm{S}}}$ nostic criteria used (Schlichter et al., 1954; $\overbrace{\overparen{\odot}}$ Schattenberg et al., 1970; Kluge et al., 1971). As a left ventricular aneurysm may develop as earlyos as two days after infarction, or remain unrecog- $\overrightarrow{0}$ nized for several years, an aneurysm should besuspected in any patient following myocardiale infarction whose recovery is not prompt or complete, especially when there is persistent conges- $x$ tive heart failure (Lam et al., 1966; Cooley and ${ }^{\omega}$ Hallman, 1968; Favaloro et al., 1968; Schattenberg et al., 1970). In our series, the earliestr diagnosis was made 23 days after causativeo myocardial infarction. Predisposing factors, such as hypertension which increases the transmurati tension exerted against the functionless portion of the ventricular wall, reported by others, were not conclusive in our series (Schlichter et al., 1954; Harley, 1969; Davis and Ebert, 1972). Aneurysme formation is more commonly seen in males, ando although younger people are not exempt, most occur in the 60-70 year age group.

The anterolateral free wall and the apex of thes left ventricle supplied by the anterior descendingo branch of the left coronary artery are the mos? usually affected areas. This is confirmed in the present series (Table II).

Posterior aneurysms are associated with occlusion of the right or circumflex coronary artery of both. Although posterior myocardial infarctions. are common, development of a posterior ventri cular aneurysm is not. This is possibly explained by the fact that such infarcts can involve the posterior papillary muscle and the resulting severe mitral regurgitation superimposed on the acutis myocardial infarction precipitates fatal left ventri윽 cular failure (Abrams et al., 1963; Favaloro et al. 1968; Harley, 1969; Ibarra-Pérez and Lillehei 1969; Schattenberg et al., 1970; Loop et al., 1973)응 In our series, both posterior aneurysms (and the superior aneurysm) were associated with mitrab regurgitation (two) or ventricular septal defect (one).

Patients with aneurysm are usually sympto $-\overline{-}$ matic and often severely incapacitated by heart failure, arrhythmias, and angina, which frequentlye prove refractory to medical treatment. Peripheraß embolism and rupture of a true aneurysm are the least common complications. As the developmen 5 of an aneurysm markedly reduces life expectancy aneurysmectomy should be carried out with markedly improved overall survival (Schlichte 0 et al., 1954; Dubnow et al., 1965; Cooley and Hall 
man, 1968; Key, Aldridge, and MacGregor, 1968; Thind et al., 1971; Davis and Ebert, 1972; Rosenthal, Daroca, and Cohen, 1972; Rao et al., 1974).

Left ventricular angiography outlines the aneurysm and confirms the integrity of the septum and the mitral valve. Selective coronary angiography indicates the feasibility of direct myocardial revascularization, which probably improves the long-term results (Davis et al., 1973; Merin et al., 1973; Gerbode et al., 1974; Cooperman et al., 1975). The usual haemodynamic parameters, such as the left ventricular end-diastolic pressure and the cardiac index, appear to have relatively little prognostic value (Key et al., 1968; Manvi, Allen and Ellestad, 1974; Cooperman et al., 1975). The majority of patients in our series had an elevated left ventricular end-diastolic pressure, but here there was no correlation with the operative results.

As time is needed for the necrotic wall of the left ventricle to be converted into fibrous tissue, a time interval of three to six months between myocardial infarction and aneurysm resection has been quoted as critical to the results of surgery (Cooley and Hallman, 1968; Favaloro et al., 1968; Kluge et al., 1971; Gerbode et al., 1974). In our series, three patients were operated upon within three months of infarction; it is felt that no arbitary time lapse should be allowed to affect clinical judgement as to the timing of surgery. All patients who underwent surgery for arrhythmias were relieved of them, and in all survivors in congestive heart failure before surgery the cardiac status has markedly improved. The immediate and late results of resection of left ventricular aneurysms in our small series compare very favourably with others (Cooperman et al., 1975).

The relatively small number receiving coronary bypass grafts does not indicate a reluctance to combine aneurysmectomy with a revascularization procedure. It reflects that fact that, in 18 of 20 patients, either the remainder of the coronary arterial tree was not sufficiently badly diseased to require grafting, or the diseased coronary arteries were considered not suitable for grafting.

We are grateful to Dr. Alan Johnson and to Dr. Neville Conway for cardiological help with these cases, and to Dr. Ivan Hyde for radiological assistance.

\section{REFERENCES}

Abrams, D. L., Edelist, A., Luria, M. H., and Miller, A. J. (1963). Ventricular aneurysm. Circulation, 27, 164.

Austen, W. G. (1973). Surgical treatment of ventricular aneurysms. New England Journal of Medicine, 288, 264.
Cooley, D. A., Collins, H. A., Morris, G. C., Jr., and Chapman, D. W. (1958). Ventricular aneurysm after myocardial infarction. Journal of the American Medical Association, 167, 557.

__ and Hallman, G. L. (1968). Surgical treatment of left ventricular aneurysm: experience with excision of postinfarction lesions in 80 patients. Progress in Cardiovascular Diseases, 11, 222.

Cooperman, M., Stinson, E. B., Griepp, R. B., and Shumway, N. E. (1975). Survival and function after left ventricular aneurysmectomy. Journal of Thoracic and Cardiovascular Surgery, 69, 321.

Davis, R. W. and Ebert, P.A. (1972). Ventricular aneurysm, a clinical-pathologic correlation. American Journal of Cardiology, 29, 1.

Davis, Z., Borman, J. B., Freund, U., and Stern, S. (1973). Closure of postinfarction ventricular septal defect, left ventricular aneurysmectomy and coronary artery bypass graft. Thorax, 28, 650 .

Dubnow, M. H., Burchell, H. B., and Titus, J. L. (1965). Postinfarction ventricular aneurysm. A clinicomorphologic and electrocardiographic study of 80 cases. American Heart Journal, 70, 753.

Favaloro, R. G., Effler, D. B., Groves, L. K., Westcott, R. N., Suarez, E., and Lozada, J. (1968). Ventricular aneurysm--clinical experience. Annals of Thoracic Surgery, 6, 227.

Gerbode, F., Kerth, W. J., Hill, J. D., Banerjee, S., and Marcelletti, C. (1974). Elective operations for left ventricular asynergy. Thorax, 29, 282.

Gorlin, R., Klein, M. D., and Sullivan, J. M. (1967). Prospective correlative study of ventricular aneurysm. American Journal of Medicine, 42, 512.

Harley, H. R. S. (1969). Cardiac ventricular aneurysm. Thorax, 24, 148.

Ibarra-Pérez, C. and Lillehei, C. W. (1969). Resection of postinfarction ventricular aneurysms, and simultaneous myocardial revascularization. Journal of Cardiovascular Surgery, 10, 419.

Key, J. A., Aldridge, H. E., and MacGregor, D. C. (1968). The selection of patients for resection of left ventricular aneurysm. Journal of Thoracic and Cardiovascular Surgery, 56, 477.

Kluge, T. H., Ullal, S. R., Hill, J. D., Kerth, W. J., and Gerbode, F. (1971). Dyskinesia and aneurysm of the left ventricle. Surgical experience in 36 patients. The Journal of Cardiovascular Surgery, 12. 273.

Lam, C. R., Taber, R. E., Gale, H. H., and Ormond, R. S. (1966). Diagnosis and surgical treatment of post-infarction left ventricular aneurysms. Diseases of the Chest, 49, 628.

Likoff, W. and Bailey, C. P. (1966). Ventriculoplasty: excision of myocardial aneurysm. Journal of American Medical Association, 158, 915.

Loop, F. D. (1971). Ventricular aneurysmectomy. Surgical Clinics of North America, 51, 1071.

Effler, D. B., Webster, J. S., and Groves, L. K. (1973). Posterior ventricular aneurysms. New England Journal of Medicine, 288, 237. 
Manvi, K. N., Allen, W. H., and Ellestad, M. H. (1974). Left atrial 'kick'. Its prognostic value in left ventricular aneurysmectomy. Journal of Cardiovascular Surgery, 15, 418.

Merin, G., Schattenberg, T. T., Pluth, J. R., Wallace, R. B., and Danielson, G. K. (1973). Surgery for postinfarction ventricular aneurysm. Annals of Thoracic Surgery, 15, 588.

Rao, G., Zikria, E. A., Miller, W. H., Samadani, S. R., and Ford, W. B. (1974). Experience with 60 consecutive ventricular aneurysm resections. Circulation, Supplement II, pp. 49 and 50, 149.

Rosenthal, J. E., Daroca, P. J., Jr., and Cohen, L. S. (1972). Rupture of chronic left ventricular aneurysm after acute coronary thrombosis. American Journal of Cardiology, 30, 547.

Schattenberg, T. T., Giuliani, E. R., Campion, B. C., and Danielson, C. K., Jr. (1970). Postinfarction ventricular aneurysm. Mayo Clinic Proceedings, 45, 13.
Schlichter, J., Hellerstein, H. K., and Katz, L. N. $\stackrel{\overrightarrow{\bar{P}}}{+}$ (1954). Aneurysm of the heart: a correlative study of one hundred and two proved cases. Medicine, 33, 43.

Tassel, R. A. V. and Edwards, J. E. (1972). Rupture of heart complicating myocardial infarction. $\frac{O}{\mathrm{C}}$
Chest, 61, 104.

Telling, M. and Wooler, G. H. (1961). Excision of $\vec{\circ}$ cardiac aneurysm. Lancet, 2, 181.

Thind, G. S., Blakemore, W. S., and Zinsser, H. F. (1971). Ventricular aneurysmectomy for the treatment of recurrent ventricular tacharrhythmia. American Journal of Cardiology, 27, 690 .

Requests for reprints to: J. K. Ross, FRCS, Wessex은 Cardiac and Thoracic Centre, Southampton WesternHospital, Southampton SO9 4QW. 